\title{
Research on Youth Values in the Guangdong-Hong Kong-Macao Greater Bay Area in the New Era
}

\author{
Lihong Zhong ${ }^{1}$, Zhihong Deng ${ }^{1}$, ${ }^{*}$ Zhenhong $\mathrm{Xia}^{2}$, Boxin Zeng ${ }^{3}$

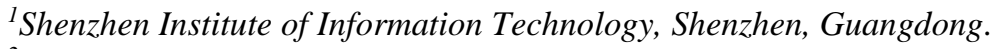 \\ ${ }^{2}$ Xia's Business Services Company, Hong Kong. \\ ${ }^{3}$ Commerce Academy, Macau University of Science and Technology, Macau. \\ *Corresponding author. Email: ezi007@163.com.
}

\begin{abstract}
The purpose of this paper is to construct the Youth Value Scale of the Guangdong-Hong Kong-Macao Greater Bay Area, and investigate and compare the current situation of youth values in the Guangdong-Hong Kong-Macao Greater Bay Area with the designed scale. The Youth Value Scale of the Guangdong-Hong Kong-Macao Greater Bay Area was constructed by identifying the main factors that explain the youth values based on the characteristics of Lingnan culture. Exploratory factor analysis and confirmatory factor analysis were carried out for the scale. Seven dimensions of the youth values: "National Identity", "Family Happiness", "Enjoyment of Happiness", "Social Harmony", "Pioneering and Innovation", "Forge Ahead" and "Wealth and Status" were identified. Based on these factors, this paper compares the similarities and differences in the ranking of youth values in Guangdong, Hong Kong and Macao thoroughly. Practically, This paper may fill in the gaps in the study of youth values in the Guangdong-Hong KongMacao Greater Bay Area, providing a good example for the study of regional values. It can also provide decisionmaking grounds for guiding youth in the Guangdong-Hong Kong-Macao Greater Bay Area to establish correct values.
\end{abstract}

Keywords: Guangdong-Hong Kong-Macao Greater Bay Area, youth; values, scale development, horizontal comparison.

\section{INTRODUCTION}

On February 18, 2019, the CPC Central Committee and the State Council issued the outline of the development plan for the Guangdong-Hong KongMacao Greater Bay Area(GBA). The Guangdong-Hong Kong-Macao Greater Bay Area(GBA) becomes one of the regions with the highest degree of openness and the strongest economic vitality in China, and the development of GBA is a major national development strategy. However, the Guangdong-Hong Kong-Macao Greater Bay Area faces the challenge of synergistic development of the three areas due to the historical, institutional, and legal differences since modern times. One of the biggest obstacles is the differences in values and lifestyles, especially among young people. Therefore, it is necessary to have an in-depth understanding of the current situation of values held by the youth in the Guangdong-Hong Kong-Macao Greater Bay Area because young people are the future leaders and main builders of GBA, and their personal values will influence their behavior and determine the development of the region.

Although there have been some domestic studies on the theoretical aspects of the values of GuangdongHong Kong-Macao Greater Bay Area, there is a lack of empirical studies and comparative analysis. In addition, although foreign scholars have developed many wellestablished value scales, these scales are not fully applicable to measuring Chinese values. As for Chinese values scales developed by domestic scholars, the main deficiency is that they fail to fully consider the regional characteristics of the values of people in a certain region. Regarding the study of youth values in the Guangdong-Hong Kong-Macao Greater Bay Area, the existing studies lack a unified values scale with regional characteristics, which makes it impossible to fully compare the youth values in Guangdong, Hong Kong and Macao horizontally and show their specific differences. 


\section{LITERATURE REVIEW}

\subsection{Research status of Chinese youth values}

In theoretical study, many scholars have analyzed the transformation and changes of Chinese youth values. For example, Wei Lili (2016) used the theory of intergenerational value transformation to compare the values of the post-90 s and post-80 s [1]; Yang Jing and Kou Qingjie (2018) studied the transformation and evolution of youth values in the past 40 years of reform and opening up [2]. Many other scholars have studied the cultivation of youth values. For example, Yu Junru and Dong Xiang (2010) analyzed the realistic background, basic content and cultivation mechanism of shaping youth core values [3]; Ren Peng (2018) studied the current characteristics, evolution logic and consolidation strategies of mainstream values of Chinese youth [4].

In the empirical study, the early studies mainly adopted the mature foreign scales. Typical studies include: Huang Xiting et al. (1989) used Rokeach's RVS [5] to investigate values of young students in five cities in China [6]; Shen Panyan et al. (2017) used Rokeach's RVS to investigate the values of teenagers in 2015, and compared the results with those in 1987, 1998 and 2004 [7]. With more and more empirical studies, many localization scales of Chinese youth values have been developed by domestic scholars, such as Wen Ping et al. (2005, 2008) [8,9], Xu Huachun et al. (2008) [10] and Wang Xiaofeng et al. (2018) [11].

\subsection{A comparative study on the values of youth in Hong Kong, Macao and the mainland}

While there have been a few studies on the youth values in Hong Kong and Macao, less studies have been conducted on comparison of the youth values of the two areas with those of the mainland. Some scholars have theoretically explored the values of Hong Kong and Macao youth. Yang Hongliu and Zhong Minghua (2017) discussed the political values of Hong Kong youth's national identity [12]. Chen Liwei (2017) studied the correspondence between core values of Hong Kong and socialist core values, and pointed out that socialist core values basically covered the core values of Hong Kong [13].

In the empirical research, some scholars have adopted the mature foreign values scale. For example, Yang Xiong (1996) used Rokeach's RVS to investigate the life values of Macao teenagers, and compared the results with those of Hong Kong and Shanghai teenagers [14]. Xu Yan and Wang Lise (2001) used Allport's SOV [15] to compare the values of college students in Beijing and Hong Kong [16]. In addition, some scholars have adopted the self-made values questionnaire. For example, Zhang Wei et al. (2008) compiled a questionnaire on youth values to investigate the characteristics and influencing factors of youth values in Guangzhou and Macao [17]. Tu Minxia et al. (2016) constructed a comprehensive concept of values composed of national identity, career outlook, outlook on life and other dimensions, and made a questionnaire survey on the values of young people in Guangzhou, Hong Kong and Macao [18]. It was found that the values of young people in Guangzhou, Hong Kong and Macao had a basic trend of coexistence of convergence and separation. However, one of the shortages of their study is that they investigated the youth values in the three cities-Guangzhou, Hong Kong and Macao, rather than The Guangdong-Hong Kong-Macao Greater Bay Area(GBA). Another shortage is that they used simple questionnaire for survey, rather than a unified youth values scale.

The literature shows that scholars at home and abroad have made abundant achievements in the research of values. Foreign scholars have developed mature value scales such as SOV [15], RVS [5] and SVS [19], but these scales are not completely suitable for measuring Chinese values. Domestic scholars such as Zhang Mengxia (2005) [20] and Jin Shenghua (2009) [21] developed the Chinese Values Scale, while Xu Huachun (2008) [10] and Wang Xiaofeng (2018) [11] developed the Chinese Youth Values Scale. The main limitations of these localized Chinese value scales are that they fail to fully consider the regional characteristics of the values of people in a certain region, and most of them use convenient samples, such as only school students in the research process.

This paper attempts to construct the GBA youth values scale by combining qualitative and quantitative methods based on the Lingnan culture shared by GBA, and analyzes and compares the similarities and differences of the youth values in Guangdong, Hong Kong and Macao. This study attempts to provide decision-making grounds for cultivating correct values of the youth in Guangdong-Hong Kong-Macao Greater Bay Area.

\section{CONSTRUCTION AND VERIFICATION OF YOUTH VALUES SCALE OF THE GUANGDONG-HONG KONG-MACAO GREATER BAY AREA}

\subsection{The initial item database of the scale}

In this paper, the steps of constructing the initial item database of Greater Bay Area youth values were as follows: (1) Through extensive literature reading, some classic values scales at home and abroad were translated and sorted out. Foreign values scales mainly refer to Rokeach's RVS [5] and Schwartz's SVS [22]. The domestic values scales mainly refer to the Chinese 
values scale developed by Jin Shenghua et al. (2009) [21], Yu Guangtao et al. (2007) [23], and Pan Yu et al. (2014) [24], and the Chinese youth values scale developed by Wen Ping et al. (2005, 2008) [8,9], Xu Huachun et al. (2008) [10] and Wang Xiaofeng et al. (2018) [11]. In the process of scale design, considering the characteristics of Lingnan culture, such as competitive spirit, inclusive mind, innovative ability, seeking truth and being pragmatic [25], 55 keywords about values conforming to Lingnan culture were summarized and refined. (2) On-line survey about the recognition degree of 55 keywords was conducted among young college students in Guangdong province. The survey also contained an open-end question, requiring that the subjects listed at least five most important keywords of values they believe in. According to the results of descriptive statistical analysis, these 55 keywords were well recognized by the subjects. Then, the content mining software was used to analyze the high-frequency keywords of the values listed in the open-end question in the survey. The top 30 high-frequency keywords of values were identified. A total of 70 keywords were selected(some similar keywords were merged), presenting a preliminary picture of the values of young people in Guangdong. In order to better describe values, these words were extended into value-oriented declarative sentences, thus forming specific value items. The initial value item database of GBA youth was constructed, which contained 70 value items. The items were numbered randomly, and the numbers remained unchanged in the following analysis. The scale was designed according to a five-point Likert scale, ranging from 1 (strongly disagree) to 5 (strongly agree).

\subsection{Pre-test and further simplification of the item database}

\subsubsection{Small-scale pretest}

In order to revise and simplify the initial items, a small-scale pre-test was carried out. Based on the obtained 70 items, a questionnaire survey (trial survey) of Guangdong youth's values was designed and published on Wenjuanxing, and college students from Shenzhen, Guangdong province were invited to fill in the questionnaire with awards. A total of 938 questionnaires were collected, among which 404 valid questionnaires were retained and 346 invalid answers were excluded. Among the participants, there were 178 males, accounting for $44.06 \%$, and 226 females, accounting for $55.94 \%$, aged between 17 and 23 .

\subsubsection{Item analysis}

In order to test the appropriateness and discrimination of values items, extreme group comparison was used in item analysis [26]. In the pre- test samples, $27 \%$ of the samples (about 109 samples in this paper) from the top-down and another $27 \%$ from the bottom-up were selected, respectively, as the high and low extreme groups, according to the order of total ranking scores for the items. Then the independent sample $\mathrm{T}$ test was carried out on the mean value of the items in the high and low extreme groups. If the $\mathrm{T}$ value reached the significant level $(\mathrm{p}<0.05)$, the items had good discrimination, otherwise they could be eliminated. According to the item analysis results, 1 item was eliminated and 69 items were reserved.

\subsubsection{Preliminary exploratory factor analysis}

The exploratory factor analysis on 69 items was carried out. Before factor analysis, Cronbach's $\alpha$ of the initial scale was calculated, and its value was 0.959 , indicating that the overall reliability of the scale was extremely high. Furthermore, KMO value was $0.950(>0.7)$, Bartlett spherical test value was $16881.150(\mathrm{P}<0.001)$, satisfying the prerequisite of factor analysis.

Principal component analysis was selected as the extraction method of factors with the adoption of varimax rotation. To ensure the unidimension of items, the items that meet any one of the following conditions were deleted:(1) the commonality was less than $0.4 ;(2)$ the absolute value of factor loading was less than 0.5 ; (3) the load was greater than 0.4 on multiple factors. After many times of factor analysis, 35 items were retained and 34 items were deleted. According to the preliminary factor analysis results, a relatively clear factor structure with seven dimensions was obtained, with the cumulative explanatory variance variation of $62.477 \%$. Therefore, the revised formal scale contained 35 items. Based on the feedback from some interviewees, two doctoral supervisors and two experts in social psychology were invited to review the formal scale, and the language expressions of some items were modified, which further improved the clarity and accuracy of the items.

\subsection{Structural analysis of youth values scale of GBA}

\subsubsection{Questionnaire design}

Based on the 35 values items obtained from the pretest, a formal questionnaire on the values of young people in Guangdong, Hong Kong and Macao was compiled. According to the research needs, and taking into account the linguistic and cultural differences between Guangdong, Hong Kong and Macao, two versions of the questionnaire were designed, namely, "Guangdong Youth Values Questionnaire (Formal Survey)" and "Hong Kong and Macao Youth Values Questionnaire". 


\subsubsection{Data collection}

The data collection lasted for half a year. In data collection, various means and incentives were adopted. The survey in Guangdong mainly used the paid sample service provided by Wenjuanxing(www.wjx.cn) to conduct online questionnaire survey. In two months, a total of 1314 questionnaires were collected, among which 344 invalid questionnaires were automatically rejected by the Wenjuanxing System, and 69 unqualified questionnaires were manually rejected, and 901 valid questionnaires were retained. Of all the subjects, there were 400 males, accounting for $44.40 \%$, and 501 females, accounting for $55.60 \%$, with an average age of 22.75 years.

Affected by the COVID-19 pandemic, the survey in Hong Kong and Macau was carried out with difficulty and long time. It took half a year to obtain adequate questionnaires for the survey. The questionnaire was published on SurveyMonkey, a popular survey website in Hong Kong and Macao. Hong Kong collected 1,260 questionnaires, among which 756 invalid questionnaires were eliminated and 504 valid questionnaires were retained; A total of 524 questionnaires were collected in Macao, among which 35 invalid questionnaires were excluded, and 489 valid questionnaires were retained. Of the subjects of Hong Kong, there were 280 males, accounting for $55.60 \%$, and 224 females, accounting for $44.40 \%$, with an average age of 24.93 years; In Macao, there were 298 males, accounting for $60.90 \%$, and 191 females, accounting for $39.10 \%$, with an average age of 22.42 years.

Table 1. Factor Analysis Results of Youth Values in Guangdong-Hong Kong-Macao Greater Bay Area

\begin{tabular}{|c|c|c|c|c|c|c|c|c|}
\hline \multirow[b]{2}{*}{ Number } & \multirow[b]{2}{*}{ Items } & \multicolumn{7}{|c|}{ Factor Loading after Rotation } \\
\hline & & $\begin{array}{l}\text { Factor } 1 \\
\text { National } \\
\text { Identity }\end{array}$ & $\begin{array}{c}\text { Factor 2 } \\
\text { Family } \\
\text { Happine } \\
\text { ss }\end{array}$ & $\begin{array}{c}\text { Factor } 3 \\
\text { Enjoyment } \\
\text { of } \\
\text { Happiness }\end{array}$ & $\begin{array}{c}\text { Factor } \\
4 \\
\text { Social } \\
\text { Harmo } \\
\text { ny }\end{array}$ & $\begin{array}{c}\text { Factor } 5 \\
\text { Pioneering } \\
\text { and } \\
\text { Innovation }\end{array}$ & $\begin{array}{l}\text { Factor } \\
6 \\
\text { Forge } \\
\text { Ahead }\end{array}$ & $\begin{array}{l}\text { Factor } 7 \\
\text { Wealth } \\
\text { and } \\
\text { status }\end{array}$ \\
\hline Q32 & $\begin{array}{l}\text { As a Chinese, I am willing to wave the } \\
\text { red flag/wear the national emblem/sing } \\
\text { the national anthem }\end{array}$ & 0.919 & 0.155 & -0.076 & 0.104 & 0.090 & 0.118 & 0.086 \\
\hline Q56 & $\begin{array}{l}\text { I think the national flag/national } \\
\text { emblem/national anthem can represent } \\
\text { my identity }\end{array}$ & 0.909 & 0.148 & -0.041 & 0.077 & 0.074 & 0.125 & 0.121 \\
\hline Q3 & $\begin{array}{l}\text { I feel cordial to the Five-Starred Red } \\
\text { Flag and the March of the Volunteers }\end{array}$ & 0.905 & 0.166 & -0.039 & 0.052 & 0.094 & 0.14 & 0.077 \\
\hline Q39 & $\begin{array}{l}\text { When someone criticizes China, I feel } \\
\text { insulted }\end{array}$ & 0.882 & 0.133 & -0.037 & 0.078 & 0.099 & 0.132 & 0.137 \\
\hline Q52 & $\begin{array}{l}\text { I am a descendant of the dragon and a } \\
\text { descendant of the Chinese people }\end{array}$ & 0.880 & 0.148 & -0.050 & 0.159 & 0.059 & 0.115 & 0.132 \\
\hline
\end{tabular}

\subsubsection{Exploratory factor analysis}

In this paper, the valid questionnaires from Guangdong, Hong Kong and Macao were randomly divided into two approximate equal groups: 451 questionnaires from Guangdong, 254 from Hong Kong and 245 from Macao were selected and put together as one group, totally 950 questionnaires. One group of the samples was used for exploratory factor analysis to explore the internal structure of the values of young people in Guangdong, Hong Kong and Macao. The other group of samples was used in the subsequent

Before factor analysis, the $\mathrm{KMO}$ and Bartlett spherical test values of samples were calculated. The KMO value was 0.933 , greater than 0.7, and Bartlett spherical test value was 18727.113 , reaching the significance level of $\mathrm{P}<0.001$, which fully indicated that the data were very suitable for factor analysis. According to the results of pre-test, the number of factors was fixed at 7 . The results of exploratory factor analysis are shown in Table 1, including 30 items of 7 factors. According to the meaning of the items measured in the factors, the factors were named as National identity, Family happiness, Enjoyment of happiness, Social harmony, Pioneering and innovation, Forge ahead and Wealth and status. The variance explained by seven factors was $65.971 \%$. The factor loadings were greater than 0.5 , and there was no cross-factor, showing that the factor structure of the scale was good. confirmatory factor analysis. 


\begin{tabular}{|c|c|c|c|c|c|c|c|c|}
\hline$\overline{\mathrm{Q} 2}$ & $\begin{array}{l}\text { I hope that the country will be } \\
\text { prosperous and the people will live and } \\
\text { work in peace and contentment }\end{array}$ & 0.773 & 0.216 & 0.016 & 0.268 & 0.013 & 0.064 & 0.066 \\
\hline Q7 & $\begin{array}{l}\text { In any case, I should spend as much time } \\
\text { with my family as possible }\end{array}$ & 0.172 & 0.722 & 0.102 & 0.073 & 0.195 & 0.148 & 0.004 \\
\hline Q70 & $\begin{array}{l}\text { I think the time with my family is the } \\
\text { happiest time }\end{array}$ & 0.313 & 0.702 & 0.017 & 0.239 & 0.121 & 0.200 & 0.083 \\
\hline Q1 & $\begin{array}{l}\text { The most fundamental happiness in life } \\
\text { lies in family happiness }\end{array}$ & 0.300 & 0.702 & 0.060 & 0.200 & 0.072 & 0.146 & 0.195 \\
\hline Q43 & $\begin{array}{l}\text { Family harmony and happiness are the } \\
\text { most important goals in life }\end{array}$ & 0.176 & 0.681 & 0.205 & 0.166 & 0 & 0.161 & 0.103 \\
\hline Q62 & It's important for me to enjoy life & 0.037 & 0.019 & 0.740 & 0.294 & 0.056 & 0.086 & 0.024 \\
\hline Q18 & To enjoy the present happiness is life & -0.019 & 0.175 & 0.727 & -0.098 & 0.069 & 0.020 & 0.063 \\
\hline Q47 & $\begin{array}{l}\text { One should pursue happiness and avoid } \\
\text { suffering }\end{array}$ & -0.127 & 0.207 & 0.664 & 0.119 & 0.070 & -0.102 & 0.203 \\
\hline Q30 & $\begin{array}{l}\text { I hate the feeling of being controlled by } \\
\text { others }\end{array}$ & -0.095 & -0.113 & 0.641 & -0.057 & 0.061 & 0.195 & 0.058 \\
\hline Q16 & $\begin{array}{l}\text { It is important to make yourself happy, } \\
\text { so there is no need to think too much }\end{array}$ & 0.002 & 0.145 & 0.583 & 0.332 & 0.178 & -0.152 & 0.149 \\
\hline Q34 & $\begin{array}{l}\text { It is very important for man and nature } \\
\text { to coexist harmoniously }\end{array}$ & 0.293 & 0.269 & 0.113 & 0.687 & 0.083 & 0.181 & 0.002 \\
\hline Q6 & $\begin{array}{l}\text { It is important to protect the natural } \\
\text { environment from pollution or } \\
\text { destruction }\end{array}$ & 0.203 & 0.156 & 0.085 & 0.681 & -0.011 & 0.323 & -0.041 \\
\hline $\mathrm{Q} 4$ & $\begin{array}{l}\text { Everyone should be treated fairly, even } \\
\text { those they are unacquainted }\end{array}$ & 0.200 & 0.253 & 0.192 & 0.662 & 0.151 & 0.137 & -0.072 \\
\hline Q61 & $\begin{array}{l}\text { Compared with the people around me, I } \\
\text { usually try new products and } \\
\text { technologies first }\end{array}$ & 0.174 & 0.108 & 0.066 & -0.020 & 0.780 & -0.057 & 0.214 \\
\hline Q55 & $\begin{array}{l}\text { When new products appear, I am very } \\
\text { happy to try and use them }\end{array}$ & 0.146 & 0.096 & 0.043 & 0.267 & 0.717 & 0.077 & 0.161 \\
\hline Q17 & $\begin{array}{l}\text { I like taking risks and dare to be the first } \\
\text { mover }\end{array}$ & -0.033 & 0.073 & 0.178 & -0.159 & 0.710 & 0.306 & 0.062 \\
\hline Q42 & $\begin{array}{l}\text { I am full of curiosity about the unknown } \\
\text { field }\end{array}$ & 0.041 & 0.108 & 0.176 & 0.333 & 0.582 & 0.328 & -0.045 \\
\hline Q51 & $\begin{array}{l}\text { We must strive for progress and } \\
\text { constantly pursue higher goals }\end{array}$ & 0.306 & 0.237 & 0.023 & 0.061 & -0.008 & 0.696 & 0.049 \\
\hline Q69 & $\begin{array}{l}\text { You can't be content with the status quo, } \\
\text { you have to make yourself better }\end{array}$ & 0.136 & 0.089 & -0.038 & 0.362 & 0.176 & 0.630 & 0.233 \\
\hline Q23 & $\begin{array}{l}\text { Dare to compete and try to do better than } \\
\text { others }\end{array}$ & 0.142 & 0.207 & 0.042 & 0.166 & 0.229 & 0.601 & 0.273 \\
\hline $\mathrm{Q} 48$ & $\begin{array}{l}\text { When I encounter difficulties, I often try } \\
\text { new solutions }\end{array}$ & 0.154 & 0.252 & 0.103 & 0.221 & 0.274 & 0.540 & 0.045 \\
\hline Q25 & Money makes people's lives happier & 0.137 & 0.064 & 0.079 & 0.245 & 0.045 & 0.061 & 0.786 \\
\hline Q41 & People live to earn more wealth & 0.21 & 0.085 & 0.269 & -0.266 & 0.051 & 0.101 & 0.640 \\
\hline Q8 & $\begin{array}{l}\text { A poor life cannot be regarded as a } \\
\text { successful life }\end{array}$ & 0.081 & 0.147 & 0.036 & -0.084 & 0.067 & 0.051 & 0.628 \\
\hline
\end{tabular}




\begin{tabular}{|l|l|l|l|l|l|l|l|l|}
\hline Q24 & People of high status are enviable & 0.089 & -0.043 & 0.14 & -0.006 & 0.284 & 0.192 & 0.594 \\
\hline Initial eigenvalue & 8.930 & 3.568 & 2.148 & 1.774 & 1.311 & 1.144 & 0.916 \\
\hline Explanatory variance \% & 17.898 & 8.799 & 8.584 & 8.022 & 7.951 & 7.421 & 7.295 \\
\hline Cumulative explanatory variance \% & 17.898 & 26.697 & 35.281 & 43.303 & 51.255 & 58.676 & 65.971 \\
\hline Internal consistency & 0.903 & 0.820 & 0.747 & 0.787 & 0.754 & 0.758 & 0.684 \\
\hline
\end{tabular}

\subsubsection{Confirmatory factor analysis}

We used the other group of the samples for confirmatory factor analysis, and tested the fitting degree between the values model obtained by exploratory factor analysis, This group of the samples included 944 questionnaires, of which 450 was from Guangdong, 250 was from Hong Kong and 244 was from Macau.

(1) Model fitting and evaluation

AMOS software was used for the confirmatory factor analysis. Bootstrap ML method was used for the model parameter estimation, and the Bootstrap sample number was set to 1000 . The initial fitting results of confirmatory factor analysis are shown in Table 2 . It can be found that some absolute indexes (GFI, AGFI), relative index (NFI) and parsimony index $\left(\chi^{2} / \mathrm{df}\right)$ did not meet the recommended values. At the same time, the standardized factor loading of item Q8 was 0.485 , lower than recommended value, suggesting that the matching degree between theoretical model and data was not ideal, and the initial structural equation model needed to be revised. Therefore, the item Q8 was deleted, and the model was constantly revised by referring to the path provided by the revised index (MI) and adding some restrictions. After revision, each fitting index of the model was basically reasonable, and the standardized factor loading of each item was 0.500 at minimum and 0.963 at maximum, all significant at the level of $\mathrm{P}<0.001$. The 7 -factor structure of GBA Youth Values Scale has been verified.

Table 2. Confirmatory Factor Analysis Fitting Index Table

\begin{tabular}{|l|l|l|l|l|l|l|l|l|l|}
\hline \multirow{2}{*}{\multicolumn{1}{c|}{ Category }} & \multicolumn{3}{c|}{ Absolute index } & \multicolumn{3}{c|}{ Relative index } & & \multicolumn{2}{c|}{ Parsimony index } \\
\cline { 2 - 11 } & RMSEA & GFI & AGFI & TLI & NFI & CFI & $\chi^{2} /$ df & PGFI & PNFI \\
\hline Recommended value & $<0.08$ & $>0.90$ & $>0.90$ & $>0.90$ & $>0.90$ & $>0.90$ & $<3$ & $>0.50$ & $>0.50$ \\
\hline Initial value & 0.061 & 0.887 & 0.863 & 0.900 & 0.890 & 0.912 & 4.498 & 0.733 & 0.786 \\
\hline Corrected value & 0.041 & 0.946 & 0.924 & 0.957 & 0.948 & 0.967 & 2.604 & 0.668 & 0.717 \\
\hline
\end{tabular}

(2) Analysis of reliability and validity

The reliability of the scale was tested by SPSS, and Cronbach $\alpha$ value was 0.917 , greater than 0.7 . Checking the results of confirmatory factor analysis, the composition reliability of the seven value dimensions was greater than 0.6 , and five of them were greater than 0.7. All these indicate that the scale has good reliability.

Validity mainly includes content validity and structure validity. Content validity is a subjective index, which can be judged by qualitative methods. In this paper, the items mainly originated from the classical literature, and were revised according to the online interview. Experts were invited to examine and approve the items, and small-scale pretest was carried out. Therefore, the compilation process of this scale is relatively standard, which can guarantee the content validity.

The test of structural validity mainly focuses on convergence validity and discriminant validity. The evaluation of convergence validity is mainly based on the standardized factor loading of items and the composition reliability of each factor. According to the results of confirmatory factor analysis, the standardized factor loading of each item was not lower than 0.50 , reaching a significant level. At the same time, the composition reliability of each factor was greater than 0.6 , indicating that the scale has good convergence validity. According to the method proposed by Anderson and Gerbing (1988) [27], the discriminant validity was tested. The results show that the chi-square value of the limited model among the seven values dimensions was significantly higher than that of the unlimited model, indicating that the factor structure of the scale had a better discriminant validity.

\section{ANALYSIS AND COMPARISON OF THE SIMILARITIES AND DIFFERENCES OF GBA YOUTH VALUES}

The two groups of samples for the exploratory factor analysis and confirmatory factor analysis were put together, so as to deeply study the general characteristics and the specific differences of the youth values in the three areas. The sample data contained 1894 questionnaires in total, including 901 of Guangdong, 504 of Hong Kong and 489 of Macao. For the convenience of comparison, the variables such as age, education background and identity were recoded.

In order to examine the overall youth values in GBA and present a profile of youth values in GBA comprehensively, the overall average scores of seven 
values dimensions were calculated by using the total sample data. At the same time, the average score of each values dimension was calculated based on demographic variables, such as gender and age, as shown in Table 3.

Table 3. Overall Mean of Youth Values in GBA

\begin{tabular}{|c|c|c|c|c|c|c|c|c|c|c|c|}
\hline \multirow[b]{2}{*}{$\begin{array}{c}\text { Values } \\
\text { Dimensions }\end{array}$} & \multirow[b]{2}{*}{$\begin{array}{c}\text { Overall } \\
\text { Mean } \\
\mathrm{N}=189 \\
4\end{array}$} & \multicolumn{2}{|c|}{ Gender } & \multicolumn{3}{|c|}{ Age } & \multicolumn{3}{|c|}{ Education Background } & \multicolumn{2}{|c|}{ Identity } \\
\hline & & $\begin{array}{c}\text { Male } \\
\mathrm{N}=97 \\
8\end{array}$ & $\begin{array}{l}\text { Female } \\
N=916\end{array}$ & $\begin{array}{c}\geq 20 \\
\mathrm{~N}=67 \\
1\end{array}$ & $\begin{array}{c}21-24 \\
N=583\end{array}$ & $\begin{array}{c}\leq 25 \\
\mathrm{~N}=640\end{array}$ & $\begin{array}{c}\text { Middle } \\
\text { School } \\
\text { Studen } \\
\mathrm{t} \\
\mathrm{N}=255\end{array}$ & $\begin{array}{c}\text { College } \\
\text { Student } \\
\mathrm{N}=148 \\
3\end{array}$ & $\begin{array}{c}\text { Postgraduat } \\
\mathrm{e} \\
\mathrm{N}=156\end{array}$ & $\begin{array}{c}\text { Students } \\
\text { in School } \\
\mathrm{N}=1190\end{array}$ & $\begin{array}{c}\begin{array}{c}\text { Incumben } \\
\text { cy }\end{array} \\
\mathrm{N}=704\end{array}$ \\
\hline $\begin{array}{l}\text { National } \\
\text { identity }\end{array}$ & $\begin{array}{c}3.599 \\
(1.299)\end{array}$ & $\begin{array}{c}3.498 \\
(1.287 \\
)\end{array}$ & $\begin{array}{c}3.707 \\
(1.305)\end{array}$ & $\begin{array}{c}3.708 \\
(1.279 \\
)\end{array}$ & $\begin{array}{c}3.799 \\
(1.132 \\
)\end{array}$ & $\begin{array}{c}3.303 \\
(1.408)\end{array}$ & $\begin{array}{c}2.666 \\
(1.449)\end{array}$ & $\begin{array}{c}3.789 \\
(1.200)\end{array}$ & $\begin{array}{c}3.323 \\
(1.254)\end{array}$ & $\begin{array}{c}3.697 \\
(1.205)\end{array}$ & $\begin{array}{c}3.434 \\
(1.430)\end{array}$ \\
\hline $\begin{array}{l}\text { Family } \\
\text { happiness }\end{array}$ & $\begin{array}{c}3.884 \\
(0.746)\end{array}$ & $\begin{array}{c}3.905 \\
(0.722 \\
)\end{array}$ & $\begin{array}{c}3.861 \\
(0.771)\end{array}$ & $\begin{array}{c}3.860 \\
(0.748 \\
)\end{array}$ & $\begin{array}{c}3.925 \\
(0.699 \\
)\end{array}$ & $\begin{array}{c}3.871 \\
(0.786)\end{array}$ & $\begin{array}{c}3.515 \\
(0.953)\end{array}$ & $\begin{array}{c}3.950 \\
(0.681)\end{array}$ & $\begin{array}{c}3.851 \\
(0.782)\end{array}$ & $\begin{array}{c}3.867 \\
(0.727)\end{array}$ & $\begin{array}{c}3.911 \\
(0.778)\end{array}$ \\
\hline $\begin{array}{l}\text { Enjoyment of } \\
\text { happiness }\end{array}$ & $\begin{array}{c}3.770 \\
(0.666)\end{array}$ & $\begin{array}{c}3.783 \\
(0.671 \\
)\end{array}$ & $\begin{array}{c}3.756 \\
(0.662)\end{array}$ & $\begin{array}{c}3.713 \\
(0.691 \\
)\end{array}$ & $\begin{array}{c}3.791 \\
(0.647 \\
)\end{array}$ & $\begin{array}{c}3.811 \\
(0.654)\end{array}$ & $\begin{array}{c}3.825 \\
(0.822)\end{array}$ & $\begin{array}{c}3.761 \\
(0.626)\end{array}$ & $\begin{array}{c}3.762 \\
(0.754)\end{array}$ & $\begin{array}{c}3.735 \\
(0.675)\end{array}$ & $\begin{array}{c}3.829 \\
(0.647)\end{array}$ \\
\hline $\begin{array}{l}\text { Social } \\
\text { harmony }\end{array}$ & $\begin{array}{c}4.162 \\
(0.700)\end{array}$ & $\begin{array}{c}4.086 \\
(0.705 \\
)\end{array}$ & $\begin{array}{c}4.243 \\
(0.686)\end{array}$ & $\begin{array}{c}4.190 \\
(0.705 \\
)\end{array}$ & $\begin{array}{c}4.170 \\
(0.677 \\
)\end{array}$ & $\begin{array}{c}4.125 \\
(0.715)\end{array}$ & $\begin{array}{c}4.112 \\
(0.821)\end{array}$ & $\begin{array}{c}4.190 \\
(0.674)\end{array}$ & $\begin{array}{c}3.972 \\
(0.697)\end{array}$ & $\begin{array}{c}4.137 \\
(0.705)\end{array}$ & $\begin{array}{c}4.204 \\
(0.690)\end{array}$ \\
\hline $\begin{array}{l}\text { Pioneering } \\
\text { and } \\
\text { innovation }\end{array}$ & $\begin{array}{c}3.432 \\
(0.744)\end{array}$ & $\begin{array}{c}3.499 \\
(0.752 \\
)\end{array}$ & $\begin{array}{c}3.361 \\
(0.729)\end{array}$ & $\begin{array}{c}3.406 \\
(0.749 \\
)\end{array}$ & $\begin{array}{c}3.437 \\
(0.678 \\
)\end{array}$ & $\begin{array}{c}3.455 \\
(0.796)\end{array}$ & $\begin{array}{c}3.219 \\
(0.870)\end{array}$ & $\begin{array}{c}3.456 \\
(0.701)\end{array}$ & $\begin{array}{c}3.556 \\
(0.856)\end{array}$ & $\begin{array}{c}3.449 \\
(0.719)\end{array}$ & $\begin{array}{c}3.403 \\
(0.786)\end{array}$ \\
\hline Forge ahead & $\begin{array}{c}3.916 \\
(0.654)\end{array}$ & $\begin{array}{c}3.905 \\
(0.665 \\
)\end{array}$ & $\begin{array}{c}3.929 \\
(0.641)\end{array}$ & $\begin{array}{c}3.975 \\
(0.633 \\
)\end{array}$ & $\begin{array}{c}3.868 \\
(0.668 \\
)\end{array}$ & $\begin{array}{c}3.899 \\
(0.658)\end{array}$ & $\begin{array}{c}3.682 \\
(0.809)\end{array}$ & $\begin{array}{c}3.956 \\
(0.610)\end{array}$ & $\begin{array}{c}3.926 \\
(0.692)\end{array}$ & $\begin{array}{c}3.937 \\
(0.641)\end{array}$ & $\begin{array}{c}3.882 \\
(0.673)\end{array}$ \\
\hline $\begin{array}{l}\text { Wealth and } \\
\text { status }\end{array}$ & $\begin{array}{c}3.214 \\
(0.734)\end{array}$ & $\begin{array}{c}3.280 \\
(0.735 \\
) \\
\end{array}$ & $\begin{array}{c}3.142 \\
(0.726)\end{array}$ & $\begin{array}{c}3.252 \\
(0.741 \\
) \\
\end{array}$ & $\begin{array}{c}3.261 \\
(0.720 \\
)\end{array}$ & $\begin{array}{c}3.130 \\
(0.732)\end{array}$ & $\begin{array}{c}3.044 \\
(0.919)\end{array}$ & $\begin{array}{c}3.244 \\
(0.690)\end{array}$ & $\begin{array}{c}3.200 \\
(0.761)\end{array}$ & $\begin{array}{c}3.280 \\
(0.731)\end{array}$ & $\begin{array}{c}3.101 \\
(0.725)\end{array}$ \\
\hline
\end{tabular}

\subsection{The mean value and ranking of the overall scores of the youth values in $G B A$}

According to the overall mean of the 7 dimensions(Table 3), the ranking order of youth values in GBA from most important to less important are Social harmony, Forge ahead, Family happiness, Enjoyment of happiness, National identity, Pioneering and innovation, and Wealth and status. Social harmony comes first, and wealth and status comes last. According to the statistical results of gender, age, education background and identity, there are subtle differences in the ranking of values among different groups.

\subsection{Ranking and comparison of mean values scores of youth in Guangdong, Hong Kong and Macao}

Table 4 shows the average scores and the rankings of values of youth in Guangdong, Hong Kong and Macao. 
Table 4. Comparison of the average scores of youth values in Guangdong, Hong Kong and Macao

\begin{tabular}{|c|c|c|c|c|c|c|c|c|}
\hline \multirow{2}{*}{$\begin{array}{l}\text { Value } \\
\text { Dimension }\end{array}$} & \multicolumn{2}{|c|}{ Overall Mean $(\mathrm{N}=1894)$} & \multicolumn{2}{|c|}{$\begin{array}{c}\text { Youth in } \\
\text { Guangdong(N=901) }\end{array}$} & \multicolumn{2}{|c|}{$\begin{array}{l}\text { Youth in Hong } \\
\text { Kong }(\mathrm{N}=504)\end{array}$} & \multicolumn{2}{|c|}{$\begin{array}{c}\text { Youth in } \\
\text { Macao(N=489) }\end{array}$} \\
\hline & Average & Rank & Average & Rank & Average & Rank & Average & Rank \\
\hline $\begin{array}{l}\text { National } \\
\text { identity }\end{array}$ & $\begin{array}{c}3.599 \\
(1.299)\end{array}$ & 5 & $\begin{array}{l}4.515 \\
(0.475)\end{array}$ & 1 & $\begin{array}{c}1.946 \\
(1.068)\end{array}$ & 7 & $\begin{array}{c}3.617 \\
(0.767)\end{array}$ & 5 \\
\hline $\begin{array}{l}\text { Family } \\
\text { Happiness }\end{array}$ & $\begin{array}{c}3.884 \\
(0.746)\end{array}$ & 3 & $\begin{array}{c}4.123 \\
(0.573)\end{array}$ & 4 & $\begin{array}{c}3.583 \\
(0.907)\end{array}$ & 4 & $\begin{array}{c}3.753 \\
(0.700)\end{array}$ & 2 \\
\hline $\begin{array}{l}\text { Enjoyment of } \\
\text { Happiness }\end{array}$ & $\begin{array}{l}3.770 \\
(0.666)\end{array}$ & 4 & $\begin{array}{c}3.661 \\
(0.618)\end{array}$ & 5 & $\begin{array}{c}3.962 \\
(0.651)\end{array}$ & 2 & $\begin{array}{c}3.772 \\
(0.721)\end{array}$ & 1 \\
\hline $\begin{array}{l}\text { Social } \\
\text { Harmony }\end{array}$ & $\begin{array}{c}4.162 \\
(0.700)\end{array}$ & 1 & $\begin{array}{c}4.462 \\
(0.486)\end{array}$ & 2 & $\begin{array}{c}4.049 \\
(0.717)\end{array}$ & 1 & $\begin{array}{c}3.725 \\
(0.752)\end{array}$ & 4 \\
\hline $\begin{array}{l}\text { Pioneering and } \\
\text { Innovation }\end{array}$ & $\begin{array}{c}3.432 \\
(0.744)\end{array}$ & 6 & $\begin{array}{c}3.446 \\
(0.678)\end{array}$ & 6 & $\begin{array}{c}3.256 \\
(0.798)\end{array}$ & 5 & $\begin{array}{c}3.588 \\
(0.766)\end{array}$ & 6 \\
\hline Forge Ahead & $\begin{array}{l}3.916 \\
(0.654)\end{array}$ & 2 & $\begin{array}{c}4.148 \\
(0.520)\end{array}$ & 3 & $\begin{array}{c}3.669 \\
(0.715)\end{array}$ & 3 & $\begin{array}{c}3.744 \\
(0.663)\end{array}$ & 3 \\
\hline $\begin{array}{l}\text { Wealth and } \\
\text { status }\end{array}$ & $\begin{array}{c}3.214 \\
(0.734)\end{array}$ & 7 & $\begin{array}{c}3.266 \\
(0.658)\end{array}$ & 7 & $\begin{array}{c}2.910 \\
(0.832)\end{array}$ & 6 & $\begin{array}{c}3.430 \\
(0.655)\end{array}$ & 7 \\
\hline
\end{tabular}

Notes: Standard deviation is in brackets.

Compared with the overall values rankings of GBA youth, Guangdong youth ranks National identity first, and the order of other dimensions remains the same; Hong Kong youth ranks Social harmony first, and Enjoyment of happiness ahead of Forge ahead, and National identity the last, and the order of other dimensions has no change; The order of first four values of Macao youth is reversed (Enjoyment of happiness ranks first), while the order of the last three have not changed.

Compared the overall value rankings with the rankings given by Guangdong youth, the largest difference is National identify. Guangdong youth ranked National identity first, while National identify list 5 th in the overall value ranking. With the strengthening of China's comprehensive national power and its international status, Chinese people are living in peace and prosperity, and their lives are getting better. Thus, Guangdong youths have a high level of national identity and feel proud of the achievements of Guangdong and the country. In the ranking of Hong Kong youth's values, Social harmony comes first, Enjoying happiness comes second, and National identity comes last, with the lowest average score. Hong Kong youths place high importance in Social harmony because in recent years, Hong Kong has experienced social unrest, and the situation continues to be volatile, jeopardizing the economic and social development of Hong Kong. Therefore, people are longing for social harmony and stability. It is also understandable that the National identity is at the bottom by Hong Kong youth because of the erosion and infiltration of Westernstyle liberal democracy and other mainstream Western values, and the political, economic, social and cultural differences between the Mainland and Hong Kong, as well as the malicious portrayal of the negative image of the Chinese Mainland by some media. Some Hong Kong youths prefer to belonging to the "Hong Kong people" identity. In the ranking of Macao youth's values, Enjoying happiness comes first and Family happiness comes second. Although National identity comes 5 th but with a high average score of 3.6 compared with 1.9 of Hong Kong youth value. Despite being ruled by Portugal for more than 400 years, the traditional Chinese cultural philosophy has still been well preserved. Macao people are relaxed and laid-back, and enjoy the pursuit of a simple and happy life with a gentle nature. Furthermore, in the past 20 years since its return to the motherland, Macao has enjoyed economic prosperity and stability, and the standard of living of its residents has improved significantly. Macao youths also have received good education on Chinese history and patriotism since childhood, having a high sense of national belonging.

In order to show the values profile of young people in Guangdong, Hong Kong and Macao more intuitively, a radar chart is drawn according to the mean values of each dimension, as shown in Figure 1. On the whole, young people in GBA give a higher average score for Social harmony, Forge ahead, Family happiness and Enjoyment of happiness, but a lower average score for Pioneering and innovation and Wealth and status. Although the scores for National identity are as high as 3.5 points or more, the differences are obvious, with Guangdong the highest, Macao the second and Hong Kong the lowest. 


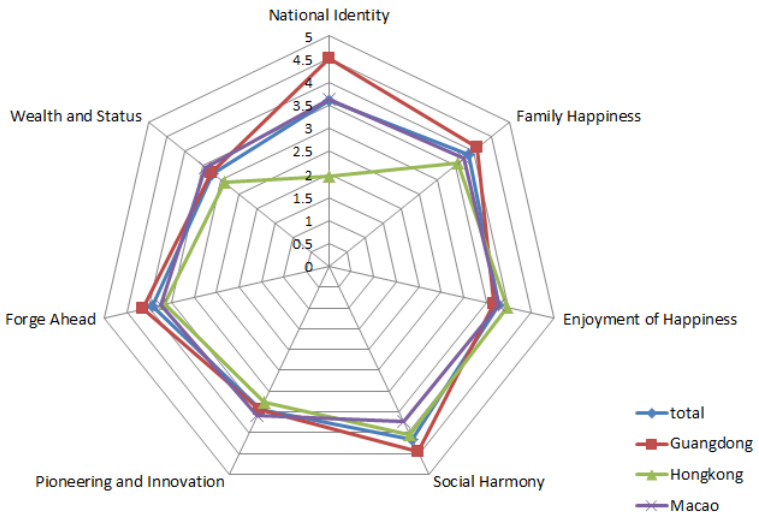

Figure 1 Radar Chart of Youth Values in GBA

\section{RESEARCH ANALYSIS AND DISCUSSION}

\subsection{The structure of youth values scale in GBA}

In this paper, the GBA Youth Values Scale was obtained through empirical research, and the sevenfactor structure of GBA values was clarified. The seven values proposed in this paper describe the whole picture of GBA youth values, and fully show that GBA youth values not only conform to the commonness of Chinese traditional culture represented by Lingnan culture, but also highlight the unique regional features. They also fully reflect the structural characteristics of GBA youth values system.

\subsection{COMPARISON OF YOUTH VALUES IN GUANGDONG, HONG KONG AND MACAO}

Generally speaking, there is little difference between the average ranking and the overall ranking of youth values in Guangdong, Hong Kong and Macao, which reveals that there are regional similarities in youth values in these areas. Such similarities provide an important ideological foundation for the coordinated development of GBA. Most young people in Guangdong, Hong Kong and Macao attach great importance to Social harmony, Forge ahead, Family happiness and Enjoyment of happiness, but pay little attention to Wealth and status. At the same time, because the young people in Guangdong, Hong Kong and Macao have grown up in different social and historical backgrounds and institutional environments, they have different understandings and views in the fields of economy, politics and life, which are reflected in certain differences in the ranking of values. It can be observed from the rankings of values that Guangdong youth ranks National identity first, with a high degree of national identity, and Social harmony second, concerning about the harmony of society; Young people in Hong Kong rank Social harmony first, valuing social harmony most, enjoying life and cherishing their own personality development, but they give low rank to National identity. Macao youth ranks Enjoyment of happiness first, paying attention to enjoying life, family happiness and national identity.

It is worth noting that although the average score of National identity is high, there are obvious regional differences, with Guangdong and Macao youths scoring higher and Hong Kong youths scoring the lowest. It shows that the youths of Guangdong and Macao have a higher sense of national belonging, while the youth of Hong Kong has a lower sense of national identity. The empirical survey data of this paper support part of research conclusions of Yang Hongliu, Zhong Minghua (2017) [12], Tu Minxia et al. (2016) [18]. Yang Hongliu and Zhong Minghua (2017) pointed out that in recent years, many political events initiated or participated by a small number of Hong Kong youth have led to the continuous deviation and deterioration of Hong Kong youth's national identity [12]. This theoretical inference is supported by the survey data in this paper, since the overall ranking of National identity of Hong Kong youth is really low. The political and academic circles should explore ways to curb the alienation and extreme trend of Hong Kong youth's political values. By improving the mechanism of "One country, Two systems" and implementing the fundamental principle of "Patriots govern Hong Kong", Hong Kong youth's sense of national honor and national identity will be enhanced, and the formation of GBA's consensus on political values will be promoted. Tu Minxia et al. (2016) pointed out that the vast majority of Hong Kong and Macao youths hold dual identities, but there is a tendency to De-Sinicization identity to a certain extent, and Hong Kong and Macao youths generally have a low degree of identity with only being the Chinese [18]. This study supports Tu Minxia's conclusion (2016) that Hong Kong youth has low sense of the identity with only being the Chinese, but has different results about Macao youth's value of national identity. According to the results of this paper, Macao youth shows higher ranking for national identity than Hong Kong youth does, which is increasingly converging with the value ranking of Guangdong youth. This may be due to various civic education that Macao has been carrying out for many years and the close exchange activities between Macao youth and the youth from mainland cities, which is worth learning from by Hong Kong youth.

\section{CONCLUSION}

\subsection{Research conclusion}

In this paper, based on the review of relevant literature in the field of values, combined with the online interviews of youth from GBA, we built an item database of GBA youth values. The online 
questionnaires for the young people from GBA was designed, and seven dimensions of GBA youth values were obtained by exploratory factor analysis, namely, National identity, Family happiness, Forge ahead, Social harmony, Enjoyment of happiness, Wealth and status and Pioneering and innovation. The results show that the value scale has good reliability and validity. Based on the sample data of questionnaire survey, this paper compares the similarities and differences of youth values in Guangdong, Hong Kong and Macao.

\subsection{Research significance}

(1) Theoretical value. Following the standard scale development process, this paper developed the GBA Youth Values Measurement Scale based on Lingnan culture, which filled the gap in the theoretical research of youth values in GBA. The scale developed in this paper provides a value measurement tool for similar research in the future, and also provides a good example for regional value research.

(2) Application value. This paper makes an in-depth investigation of the youth values of GBA, and comprehensively analyzes the similarities and differences of the youth values of the three areas, providing data support and grounds for policy-making decision and promotion of the coordinated development of GBA.

\subsection{Research limitations}

This study has some limitations. First of all, due to the impact of the COVID-19 pandemic, it is very difficult to conduct on-the-spot investigation and interview in Hong Kong and Macao, and online investigation can only be used, which may affect the research results. Secondly, this paper reveals the similarities and differences in the values of young people in Guangdong, Hong Kong and Macao. However, due to length limit, there is no further study on how to establish correct values for young people in GBA in the new era. Future research can focus on the similarities and differences of values of young people in GBA, and comprehensively explore the cultivation path for coordinated development of correct values of young people in the new era under the guidance of socialist core values

\section{ACKNOWLEDGMENTS}

2020 Youth Fund Project of Humanities and Social Sciences Research of the Ministry of Education, "Research on Guangdong-Hong Kong-Macao Greater Bay Area Youth Values in the New Era" (ProjectNo.: 20YJC 710096); In 2019, the 13th Five-Year Plan of Philosophy and Social Sciences in Guangdong Province, "Research on the Cultivation of Correct Values of
Youth in Guangdong-Hong Kong-Macao Greater Bay Area" (ProjectNo.: GD19CMK06).

\section{REFERENCES}

[1]. L. Wei, Intergenerational Value Shifts of Youth Groups: A Comparison Based on the Post-90s and Post-80s, China Youth Studies, (10), 2016, pp. 6475. (in Chinese)

[2]. J. Yang, Q. Kou, The Transformation and Transmutation of Youth Values in the 40 Years of Reform and Opening Up, Chinese Youth Social Science, 37(04), 2018, pp. 15-22. (in Chinese)

[3]. J. Yu, X. Dong, The Shaping of Youth Core Values: Realistic Background, Basic Content and Cultivation Mechanism, China Youth Studies, (04): 2010, pp. 16-20. (in Chinese)

[4]. P. Ren, The Current Characteristics, Evolutionary Logic and Consolidation Strategies of Youth Mainstream Values Formation, Journal of Ideological Theory Education, (12), 2018, pp.6771. (in Chinese)

[5]. M. Rokeach, The Nature of Human Values, New York: Free Press, 1973.

[6]. X. Huang, J. Zhang, S. Zhang, A Survey of Adolescent Students' Values in Five Cities in China, Journal of Psychology, (03), 1989, pp. 274283. (in Chinese)

[7]. P. Shen, Y. Xin, J. Gao, C. Feng, Changes in Chinese Adolescents' Values (1987-2015), Youth Studies, (04) , 2017, PP. 1-10+94. (in Chinese)

[8]. P. Wen, H. Li, Y. Peng, W. Luo, A Study of Young Students' Value Goal Structure, Psychological Science, (06), 2005, pp. 209-211. (in Chinese)

[9]. P. Wen, S. Wu, B. Pang, A Study on the Structure of Young Students' Value Means, Journal of Education, (02) , 2008, pp. 17-20. (in Chinese)

[10]. H. Xu, C. Zheng, X. Huang, A Preliminary Study on the Life Values of Chinese Youth, Journal of Southwestern University (Social Science Edition), (05), 2008, pp. 35-39. (in Chinese)

[11]. X. Wang, D. Li , X. Chen, J. Liu, Y. Dai, H. Guo, T. Xu, A Study on the Constitutive Characteristics and Adaptive Functions of New-Era Adolescents' Values, Psychological Science, 41(06), 2018, pp. 1282-1291. (in Chinese)

[12]. H. Yang, M. Zhong, From Disagreement to Consensus: An Exploration of the Political Values of National Identity Among Hong Kong Youth, Learning and Exploration, (07), 2017, pp. 79-85. (in Chinese) 
[13]. L. Chen, "Diversity and Tolerance" and "Friendliness": A Study on the Correspondence Between the Core Values of HKSAR and the Core Values of Socialism, Journal of Hangzhou Normal University (Social Science Edition), 39(03), 2017, pp. 124-127. (in Chinese)

[14]. X. Yang, A Study on the Life Values of Macau Youth, Contemporary Youth Studies, (04) 1996, pp. 8-11. (in Chinese)

[15]. G.W. Allport, P.E. Vernon, G. Lindzey, Study of Values, Boston: Houghton Mifflin, 1960.

[16]. Y. Xu, L. Wang, A Comparative Study of the Values of College Students in Beijing and Hong Kong, Psychological Exploration, (04), 2001, pp. 40-45. (in Chinese)

[17]. W. Zhang, S. Zhen, Q. Hu, A Comparative Study of Adolescent Values in Guangzhou and Macau, Journal of South China Normal University (Social Science Edition), (05), 2008, pp. 101-108+160. (in Chinese)

[18]. M. Tu, C. Li, H. Sun, Convergence or Separation: A Comparative Analysis of Youth Values in Guangzhou, Hong Kong and Macau, Youth Exploration, (02), 2016, pp: 88-100. (in Chinese)

[19]. S.H. Schwartz, Are There Universal Aspects in the Content and Structure of Values? Journal of Social Issues, 50, 1994, pp. 19-45.

[20]. M. Zhang, A Comparative Study on the Motivation of Chinese and Western Values in Consumer Purchasing Behavior, Economic Management, (08), 2005, pp.4-11. (in Chinese)

[21]. S. Jin, J. Zheng, Z. Xin, The Structure and Characteristics of Contemporary Chinese Values, Journal of Psychology, 41(10), 2009, pp.10001014. (in Chinese)

[22]. S.H. Schwartz, J. Cieciuch, M. Vecchione, E. Davidov, R. Fischer, C. Beierlein, et al., Refining the theory of basic individual values, Journal of Personality and Social Psychology, 103, 2012, pp. 663-688.

[23]. G. Yu, P. Fu, J Liu, Q. Qu, Reconciling Yin and Yang: Chinese Value Orientation and Value Structure, Nanjing Business Review, (04) 2007, pp. 1-34. (in Chinese)

[24]. Y. Pan, L. Gao, X. Zhang, Y. Wan, A Study of Consumer Values in Chinese Cultural Context: Scale Development and Comparison, Management World, (04), 2014, pp. 90-106. (in Chinese)

[25]. J. Guo, P. Zuo, Research on Lingnan Culture, Tsinghua University Press, 2015. (in Chinese)
[26]. M. Wu, The Practice of Statistical Analysis of Questionnaires: SPSS Operation and Application, Chongqing: Chongqing University Press, 2010. (in Chinese)

[27]. J.C. Anderson, D.W. Gerbing, Structural equation modeling in practice: A review and recommended two-step approach, Psychological bulletin, 103(3), 1988, pp. 411-423. 